\title{
El Palacio de Oquendo, una residencia de élite en el valle bajo del río Chillón
}

\section{The Palacio de Oquendo, an elite residence in the lower valley of the Chillón river}

\author{
Noelia Allcca Aiquipa \\ https://orcid.org/0000-0003-4714-7766 \\ Universidad Nacional Mayor de San Marcos \\ noelia.allcca@unmsm.edu.pe
}

\section{RESUMEN}

El presente trabajo de investigación es el estudio sobre la importancia, y funcionalidad del sitio arqueológico Palacio de Oquendo a partir del estudio arquitectónico. Se centrará en el estudio y análisis de los componentes arquitectónicos presentes en el sitio arqueológico Palacio de Oquendo, como en el emplazamiento y diseño arquitectónico que está presentando. En ese sentido, es relevante destacar que, a lo largo de la literatura comprendida para este sitio, se puede encontrar variedad de trabajos del sitio Palacio Oquendo estudiado grosso modo, dentro de investigaciones en el valle bajo de Chillón, en sitios arqueológicos ubicados en Oquendo y no centrándose en Palacio de Oquendo, sobre todo en la función que habría cumplido en el Horizonte Medio. Por ello, el presente trabajo pretende contribuir en el conocimiento sobre la función que cumplió y caracterizar el sitio de Palacio de Oquendo como una residencia de élite, el cual estamos postulando.

Palabras claves: Palacio; etnohistoria; arqueología; arquitectura; Intermedio Tardío; Horizonte Tardío. 


\section{ABSTRACT}

This research work is the study of the importance and functionality of the Palacio de Oquendo archaeological site, based on the architectural study. It will focus on the study and analysis of the architectural components present in the archaeological site Palacio de Oquendo, as in the site and architectural design you are presenting. In this sense, it is relevant to note that, throughout the literature included for this site, a variety of works from the Palacio Oquendo site can be found roughly studied, within investigations in the Lower Valley of Chillón, in archaeological sites located in Oquendo and not focusing on Palacio de Oquendo, especially on the role it would have fulfilled in the Middle Horizon. Therefore, the present work aims to contribute to the knowledge about the function that the Oquendo Palace played and characterize the site as an elite residence, which we are postulating.

Keywords: Palaces; Ethnohistory; Archeology; Architecture; Late Intermediate; Late Horizon.

ReCiBIDO: 20/02/2021 - AcePTADO: 25/03/2021 - PublicAdo: 25/06/2021

\section{INTRODUCCIÓN}

En el valle bajo del río Chillón se han realizado aportes de investigación significativos para periodos tempranos y tardíos. El sitio arqueológico Palacio de Oquendo ha sido estudiado solo a grosso modo como parte de investigaciones en conjunto con otros sitios arqueológicos en el valle, en inventarios, prospecciones y estudios sistematizados. Por ello, se realiza las investigaciones prudentes y específicas para el Palacio de Oquendo, sitio importante durante el Periodo Horizonte Tardío debido a la continuidad ocupacional que viene desde el Intermedio Tardío, y cuya ubicación es estratégica con alcances de recursos tanto de valle como del mar.

Durante el Intermedio Tardío tuvo una ocupación por parte de los Colli, entidad sociopolítica establecida en el valle del Chillón y su continuidad durante el Horizonte Tardío, al mando de los incas. Además, se encuentra asociado al camino inca lo cual denota la importancia dentro de la configuración del Tawantinsuyu y la asociación y comunicación presente con otros sitios importantes administrativos, políticos, que se encuentran cercanos.

\section{ANTECEDENTES}

El valle del río Chillón, a través del tiempo ha sido objeto de investigaciones etnohistóricas, como de investigaciones arqueológicas, como las investigaciones de Villar Córdoba (1935), Dillehay (1987), Silva (1992), Farfán, Bautista, Raymondi (2014) y María Rostworowski $(1977,1978)$, siendo notablemente estudiados los sitios arqueológicos ubicados en la zona del valle medio y valle alto predominantemente. A 
lo largo del valle del Chillón se pueden encontrar sitios muy tempranos hasta sitios de periodos tardíos, demostrando que el valle del Chillón tuvo una ocupación ininterrumpida a lo largo del tiempo.

La información etnohistórica señala que en el valle del Chillón, durante el Intermedio Tardío, según María Rostworowski (1972), se desarrolló un señorío denominado Collique en la zona media y baja del Chillón que abarcó desde el mar hasta algunos metros valle arriba del actual pueblo de Santa Rosa de Quives, quienes sojuzgaron etnias como: los sutcas, los sehuillays, los comas, los carahuaillos y los chuquitanta. A dicho señorío se adscriben una serie de curacazgos menores como Collec, Chuquitanta, Seuillay, Comas, Sutca y Carabayllo en el valle bajo; Sapan, Guancayo y Quibi en la margen izquierda de la cuenca media; y Macas, Guarauni y Missai en la margen opuesta de la misma sección del valle.

Según Rostworowski, a la llegada de los incas al valle del Chillón los colli habrían ya conformado una extensa macro etnia preincaica que en determinado momento habría llegado a ocupar parte del valle de Lima, pero que, al resistir a la invasión de Túpac Yupanqui, fueron derrotados, siendo reemplazado su gobernante nativo por un yanacona designado por el Inca. Los Incas hacen cambios sustanciales en las estructuras locales movilizándolas, reorganizándolas o aun aniquilándolas cuando se les oponían férreamente, como en el caso de los Quivi. Rostworowski (1967-68) menciona que los incas al eliminar a los curacas de Quivi y de Collique, impusieron el sistema mitimaes con gente de la etnia Chacalla de la zona de Yauyos.

Hugo Ludeña en el año 1970, centra sus investigaciones en el valle del Chillón con el objetivo de realizar una secuencia cronológica y cultural del valle. En donde identifica para el área de estudio en el valle bajo del río Chillón, restos de paredes de adobón y caminos epimurales en la margen izquierda del río, por la zona de Oquendo.

Dillehay $(1974,1977,1987)$ identifica tres estrategias políticas y económicas que mantuvieron en equilibrio a las etnias establecidas en el valle del Chillón durante el Intermedio Tardío: (1) cooperativas; (2) coercitivas; y (3) receptividad económica y descentralización política. Estas estrategias probablemente dieron orden a los grupos, permitiendo la interrelación, intercambio y reciprocidad tanto de manera vertical como horizontal en el valle. El río Chillón aparece como una frontera natural de dos grandes grupos étnicos susceptibles de ser distinguidos por medios arqueológicos, los límites territoriales no parecen ser rígidos sino permeables, permitiendo asentamientos que serían producto de una territorialidad salpicada. Ellos explicarían tentativamente, por ejemplo, porqué hay "conglomerados de montículos" en la banda derecha del Chillón. No existe un patrón arqueológico que pueda sugerir que existió una organización social institucionalizada con una autoridad centralizada.

El poblamiento del valle es total durante este período. Hay un mayor manejo del espacio utilizando el litoral, terrazas aluviales o pisos del valle, las laderas y cum- 
bres de los cerros y las desembocaduras de las quebradas. Aquí las distintas unidades sociopolíticas locales se asentaron y establecieron relaciones definidas por su posición en la jerarquía étnica. (Silva, 1996).

Para el caso del bajo Chillón, zona en la que centraremos nuestra investigación, Tom Dillehay (1976, p. 202) vincula el sitio de Carabayllo al curacazgo del mismo nombre y Jorge Silva (1996, p. 195) hace lo propio con lo que denomina "Complejo Chuquitanta"; mientras que ambos coinciden en caracterizar al sitio de Cerro Collique como el centro principal del señorío epónimo.

Para el Horizonte Tardío (1470-1532 d. C.), Túpac Inca Yupanqui avanzó hacia el Chillón y, aliado con los Yauyos, derrotó al señorío Colli. La configuración sociopolítica del valle del Chillón se transformó y se realizó la integración de diferentes localidades dentro del Imperio Inca. En el Valle Bajo del Chillón hay una reorganización del orden social y política, en donde los incas estarían reocupando sitios del Intermedio Tardío y siendo reemplazados muchos de ellos como parte de la organización administrativa del estado Inca.

En el valle bajo del Chillón se realizan investigaciones arqueológicas como parte de catastros y prospecciones. Silva en 1996 como parte de su tesis de doctorado, realiza un reconocimiento en el valle del Chillón y prospección, logrando evidenciar los conglomerados de montículos en el piso del valle desde Márquez-Oquendo hasta Santa Rosa de Quives y para la zona baja del Chillón, responden a un patrón de asentamiento que se distribuyen consistentemente en las terrazas aluviales entre Márquez y La Pampilla, en sentido horizontal, y entre el litoral y Santa Rosa de Quives, en sentido vertical. Sin embargo, se constata una alta concentración de estos en la margen izquierda, como ocurre en el Complejo Arqueológico Oquendo (Silva, 1996).

Para el valle bajo del Chillón, Silva menciona que se han hallado fragmentos de cerámica de tiestos incas en los montículos de Oquendo y en estructuras de tapias presentes en la base oeste del cerro Oquendo. Estos formarán parte de la red de caminos epimurales que unen Puente Inga, Tambo Inga y el Complejo de Oquendo.

Cornejo, en "La Nación Ischma y la provincia inka de Pachacamac", considerando al valle del río Lurín, Rímac y Chillón como la provincia inka durante el Horizonte Tardío. En el caso de la configuración del valle del Chillón, menciona que hubo tres señoríos o guarangas; Collique en el valle bajo, Yangas en el valle medio, y Canta, en el valle alto durante el Intermedio Tardío. Y durante el Horizonte Tardío, todos son conquistados por los Chaclla, por orden del inca.

Las investigaciones de Ronal Ayala (2008) en Cerro Respiro que se toma como referencia debido a que se encuentra a la margen contraria del sitio, sin embargo, presenta características similares en cuanto a la distribución arquitectónica, cumpliendo una función de residencia de élite en el periodo Horizonte Medio, que es lo que se propone en esta investigación para el sitio del Palacio de Oquendo. 
Espinoza (2008), es otro investigador que menciona al Palacio de Oquendo, Cerro Respiro y Tambo Inga, como conjuntos con canchones y recintos de tapia que habían cumplido funciones análogas a las presentes en el valle del Rímac durante el Horizonte Tardío, como el recinto amurallado de Maranga, cumpliendo algunas funciones como residencias y centros administrativos reservados a la élite cusqueña.

Tomamos como referencia a Espinoza (2008), y Maquera (2008), en sus investigaciones en la Huaca Aznapuquio y Huaca Naranjal respectivamente, debido a que nos dan un alcance acerca de cómo están funcionando los sitios del valle Bajo del río Chillón.

Maquera (2008), evidencia un centro de producción de cerámica de estilo Ichma en el valle del Bajo Chillón en el sitio de Huaca Naranjal. Si bien es cierto el estilo Ichma estaba dentro de una unidad social que abarcaba el valle del Rímac y el valle de Lurín, al encontrarse el sitio de Huaca Naranjal estaría denotando enclaves Ychmas fuera de sus límites políticos, y lleva a plantearse la inserción de la cultura Ychma en el valle bajo del Chillón, que cobra una fuerte deducción debido a que no se encuentra hasta el momento una definición clara de la unidad social Collique que se plantea a partir de los datos etnohistóricos.

Además, tomaremos como referencia la "Construcción, arquitectura y planeamiento Incas" de Agurto (1987), para poder analizar e identificar los elementos propios de la arquitectura Inca.

En el 2014 y parte de las investigaciones más recientes para el valle bajo del Chillón, Raymondi para el Intermedio Tardío hace referencia a que la organización del valle habría sido a través de tres esferas territoriales: Chuquitanta, Pro, Collique. En donde incluye al Palacio de Oquendo dentro de la esfera territorial Collique (figura 02).

Durante el Horizonte Tardío los incas habrían ocupado el valle de modo directo con el surgimiento de nuevos asentamientos arquitectónicos con el trazado inca, como el caso de Cerro Respiro, Tambo Inca y Palacio de Oquendo y en otros sitios realizaron sólo remodelaciones para su nueva ocupación, como el caso de Huaca Pro, Huaca Chasqui y Huaca Oquendo emergidos en un periodo precedente.

Los palacios en el caso del valle Chillón a diferencia de los que se encuentran en el valle Rímac, se observa la construcción de palacios como Palacio de Oquendo bajo la concepción netamente Inca, una concepción directa, a diferencia de otros sitios del valle de Lurín y Valle del Rímac, en donde muchos de los palacios emergidos en el intermedio Tardío se están reocupando en el Horizonte Tardío y en algunos casos construyendo nuevos, pero con influencia del precedente.

Lo mencionado da respuestas a qué tipo de ocupación habría tenido en el valle bajo del Chillón, si el de una entidad de élite local o una entidad de élite propiamente inca. 
Punto importante es el camino inca que se encuentra asociado al Palacio de Oquendo, que está conectado con la red vial inca en todo el valle del Chillón, conectando la zona de Oquendo a través de estos y en otros valles, el cual muestra la gran importancia de este sitio.

De acuerdo con los caminos inca, Agurto (1984) menciona que hubo una atención por parte de los planificadores y constructores Incas en los caminos, tratándose nuevas vías troncales y mejorando y ampliando las redes comarcanas existentes.

\section{LA ARQUITECTURA RESIDENCIAL EN LA COSTA CENTRAL}

Villacorta en sus estudios sobre los palacios en la costa central, define una residencia de élite como una residencia de un gobernante en el cual se dan una serie de pretensiones públicas: “(...) su arquitectura destaca de manera particular, es un lugar de toma de decisiones (atribución administrativa) y la materialización del poder de sus ocupantes" (Villacorta, 2004, p. 545).

Además, añade:

“... el diseño de los edificios en cuestión (v.g. palacios o residencia de élite), excede largamente a la sola función doméstica. Su complejidad se sustenta en la centralización de la toma de decisiones -exclusivas de sus ocupantes principales-, que conciernen al control, transformación y administración de los recursos materiales e ideológicos de una sociedad determinada" (Villacorta, 2004, p. 546).

(Ver figura 01).

Pillsbury (2004), quien se centra en definir un palacio en los andes, define a un palacio como: “(...) la residencia oficial de un líder religioso soberano o supremo, sostiene además que los reyes necesitaban gobernar, comer y dormir en algún lugar" (Pillsbury, 2004, p. 181).

Astuhuamán por su parte en base a sus investigaciones sobre la función de la arquitectura inca de élite en el extremo norte del Perú, define un palacio como:

“(...) una encarnación física y permanente de la autoridad. A pesar de que quizás haya múltiples palacios, construidos por la iniciativa de distintos gobernantes, individual y colectivamente ellos llegaron a ser el símbolo permanente del poder estatal y el centro de su estructura de gobierno". (Astuhuamán, 2013, p. 11).

Por otro lado, Mackey (1987, p. 126) realizó un interesante sumario en la que se pueden distinguir siete características principales:

“a) Un sector de vivienda para el administrador; b) el control de otros asentamientos; c) la administración de recursos naturales, especialmente tierras y agua; 


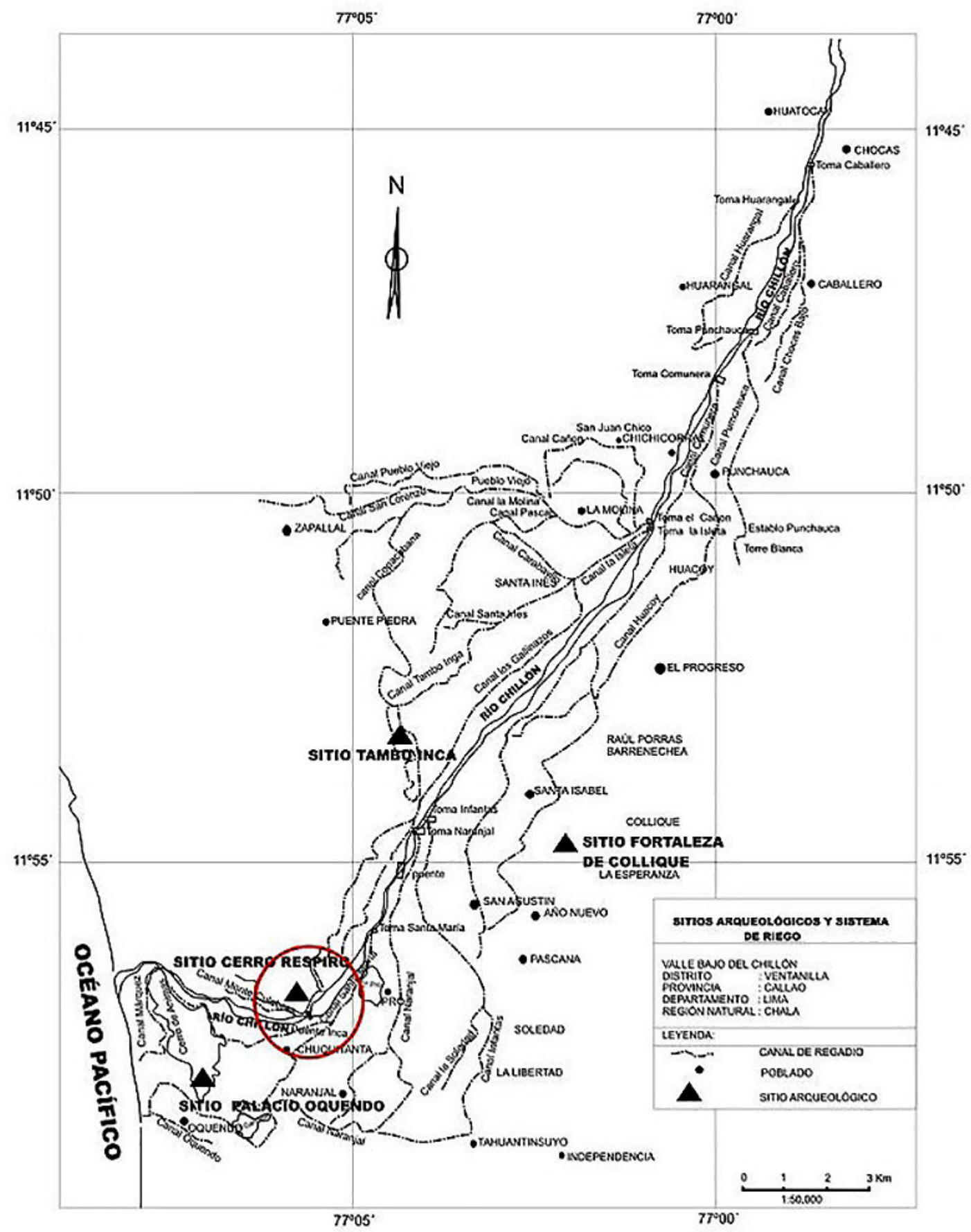

Figura 01. Sitios del Horizonte Tardío en el valle bajo del Chillón (Imagen tomada de: Ayala, 2008) 
d) el control de la fuerza de trabajo con objetivos económicos o militares; e) colecta, almacenamiento y envío de bienes; f) realización de actividades ceremoniales y religiosas, y g) control de la producción manufacturera del Estado".

Wason en sus estudios realizados en el año 1996 menciona que:

"Las residencias de élite se caracterizan por disponer de un espacio más amplio que el resto de las viviendas de la comunidad que cumplen con el mismo propósito doméstico. Esta realidad se fundamenta en el hecho de que esta «casa» es también el espacio donde se atiende a otros grupos distintos al de la familia del líder. Así, muchas de las facilidades que justifican esta amplitud encuentran su explicación en la necesidad del líder por controlar y atender aspectos como el almacenamiento de excedentes, la manufactura de objetos suntuarios, o la organización de la redistribución y las redes de intercambio. La centralización de todas estas actividades y recursos fue privilegio exclusivo del líder y fundamento de su estatus social”. (Wason, 1996, p. 141)

Villacorta encuentra rasgos que permiten caracterizar un sitio como características palaciegas, y menciona que:

“... los rasgos permiten vislumbrar a la residencia de élite como una edificación que puede ser reconocida por: a) sus características físicas, b) su tamaño "monumental"; c) su ubicación prominente; d) el uso de elementos y técnicas constructivas particulares o "más elaboradas"; e) el diseño y construcción unitario de la obra; f) por la asociación de múltiples componentes arquitectónicos formalmente diversos como parte del mismo espacio construido, donde es posible distinguir áreas públicas y otras reservadas" (Villacorta, 200, p. 546).

En base a los autores mencionados se puede inferir que una "residencia de élite" es la clara muestra de la evidencia del poder. Es un lugar que presenta una arquitectura monumental, donde se desarrollan diversas actividades, principalmente la de residir y pernoctar, como también otras series de funciones lo que lo hace un lugar multifuncional, presentando espacios públicos y espacios privados, y evidenciando una jerarquización social, con un personaje de alto estatus a la cabeza y los súbditos cumpliendo sus roles designados por la élite. Presentan un espacio de vivienda, un espacio de actividades productivas, espacios de almacenamiento, espacios de control administrativo.

\section{UBICACIÓN MARCO GEOGRÁFICO DEL PALACIO DE OQUENDO}

\section{Ubicación política del sitio}

El sitio arqueológico Palacio de Oquendo, se encuentra ubicado en la margen izquierda del valle bajo del río Chillón, en el cono de deyección de la pequeña 
quebrada del Cerro de Oquendo. El sitio se ubica en el ex fundo de Oquendo, en el distrito de Callao, en la provincia Callao, en la región de Lima. Su ubicación se encuentra en la Carta Nacional 24-i, según el Instituto Geográfico Nacional (IGN), en escala 1:100 000 (figura 02).

\section{Marco geográfico}

El sitio arqueológico Palacio de Oquendo se encuentra en la margen izquierda del valle bajo del río Chillón, emplazado en el pie del cerro Oquendo con una altitud de 25 m s. n. m., aproximadamente. Pertenece a la región geográfica Chala, una de las ocho regiones naturales según Pulgar Vidal (2014). Se ubica en las coordenadas UTM (WGS84): $8676003 \mathrm{~N}, 269362 \mathrm{E}$ y a $24 \mathrm{~m} \mathrm{s.} \mathrm{n.} \mathrm{m.}$

En la parte baja del valle del chillón donde se centra nuestra investigación se caracteriza por presentar una temperatura de $18,5^{\circ} \mathrm{C}$, siendo en los meses de verano un clima cálido con $28^{\circ} \mathrm{C}$, y en invierno $14^{\circ} \mathrm{C}$.

Las vías de acceso al sitio se dan desde la Av. Néstor Gambetta. Para llegar al sitio arqueológico Palacio de Oquendo se debe caminar desde el cruce de la Av. Néstor Gambetta con la Calle 2 en dirección a la Av. Los Alisos. Se camina de 2 a 3 cuadras hacia el este de la avenida.

La cuenca del río Chillón se ubica al norte de la ciudad de Lima, en las provincias de Lima y Canta, región de Lima. Su origen se encuentra en la laguna de Chonta a $4850 \mathrm{~m}$ s. n. m. Este río es integrante de la cuenca hidrográfica del Océano Pacífico. Limita por el norte con las cuencas de Chancay-Huaral, por el sur con la cuenca del Rímac, por el este con la cuenca del Mantaro y por el oeste con el Océano Pacífico.

El valle bajo del río Chillón comprende desde el litoral, la zona de Oquendo, Márquez hasta la zona de Trapiche, comprendiendo los distritos de Carabayllo, Puente Piedra, Collique, y las zonas de Naranjal, Oquendo y Márquez. Políticamente se encuentra ubicado en el distrito de Callao, provincia de Callao, región Lima.

La cuenca del río Chillón es de forma más o menos rectangular alargada abarcando un área de 2,300 $\mathrm{km}^{2}$ aproximadamente hasta su desembocadura en el mar. La cuenca del Río Chillón desde sus nacientes hasta el mar realiza un recorrido de $241 \mathrm{~km}$. El río tiene su origen en el Glaciar de Chontas, en la provincia de Huarochirí a 5,000 m de altitud. La cuenca del río Chillón cuenta con un área de drenaje total hasta su desembocadura en el mar de $1.241 \mathrm{~km}^{2}$, con una pendiente de $1.775 \%$. El río Chillón recorre por un lecho encajonado formando un valle de mediana amplitud.

La zona baja del río Chillón se caracteriza por presentar una configuración amplia, conformado por terrazas inundables y no inundables, áreas planas en ambas márgenes del río y un cauce o lecho accidentado por donde discurren las aguas del río Chilón. La topografía en esta área es plana y ligeramente ondulada, por encontrarse en la zona aluvial del valle. (Dirección ral de Aguas y Suelos). 

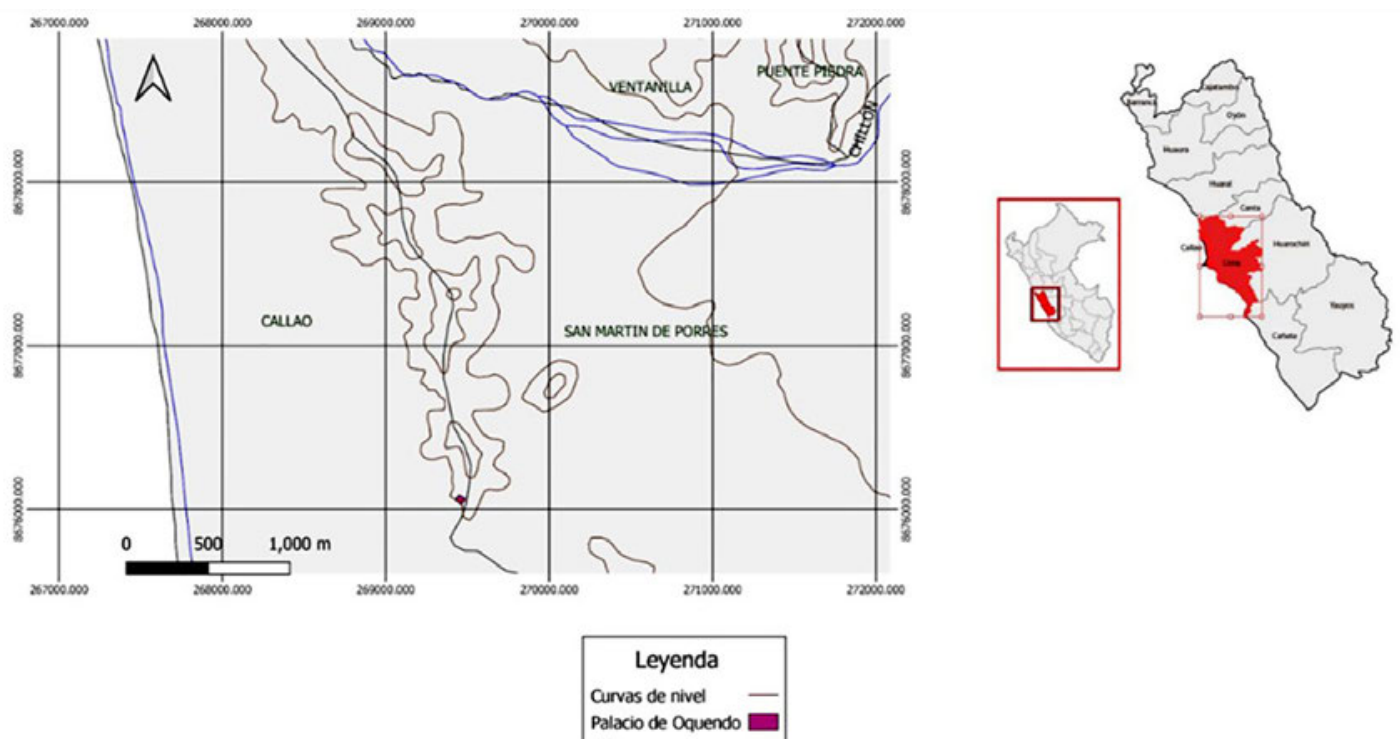

Figura 02. Ubicación del sitio Palacio de Oquendo.

\section{PALACIO DE OQUENDO: EMPLAZAMIENTO Y ANÁLISIS DE LA ARQUITECTURA}

\section{Emplazamiento}

El sitio arqueológico Palacio de Oquendo se encuentra emplazado en un área estratégica, en el cono de deyección de la pequeña quebrada del Cerro de Oquendo, con una altitud de $25 \mathrm{~m} \mathrm{~s}$. n. m., aproximadamente, el cual sugiere que la función del sitio gira en torno a la red económica de esta parte del valle.

Este sitio habría tiene una funcionalidad importante debido al acceso de recursos naturales, como del litoral marino ya que se encuentra muy cercanamente al mar, además de encontrarse con un acceso a los terrenos de cultivo y a los terrenos de la parte baja del río Chillón ubicados entre el mar y Oquendo que fueron zonas húmedas. Lo cual sugiere un control del sitio con respecto a los terrenos de cultivo, los recursos del mar e intercambio de productos.

\section{Sectorización}

El sitio arqueológico Palacio de Oquendo se dividió en dos sectores, debido a que el sector 1 presenta una distribución más compleja que el sector 2 . El sector, presenta una mayor distribución de espacios internos de forma funcional, en el que se encuentran patios, espacios habitacionales y pasadizos que permiten la comunicación de un recinto con otro. El sector 2, más bien presenta un espacio abierto delimitados por muros de tapiales, que encierran el espacio cuadrangular, y presenta el ingreso por la parte NO del sector 2 (figuras 03 y 04). 


\section{Análisis arquitectónico}

\section{Sector 1:}

El sector 1 se encuentra ubicado en el cono de deyección del cerro Oquendo. Se encuentra ubicado a $11^{\circ} 58^{\prime} 7.73^{\prime \prime} \mathrm{S} 77^{\circ} 7^{\prime} 4.65^{\prime \prime} \mathrm{O}$. Está conformado por un conjunto de recintos de planta trapezoidal construidos en base a tapiales en bloques y en algunos casos con base de piedras, dispuestos en forma en patios o espacios públicos (figura 05).

\section{Dividimos en 6 recintos al primer sector:}

Recinto 1: Corresponde a un espacio público o de trabajo. Tiene $17 \mathrm{~m}$ de largo por $15 \mathrm{~m}$ el ancho máximo. Se encuentra delimitados por muros altos que le dan la forma trapezoidal. Los muros que delimitan este subsector son: el muro 3, muro $2 \mathrm{~b}$, muro 4a y el muro 6 (figura 6). Los muros que delimitan al recinto se encuentran construidos con base de piedras canteadas unidas con argamasa sobre el cual se construyeron los tapiales.

Muro 3: Tiene 8,30 $\mathrm{m}$ de alto, 0,56 $\mathrm{m}$ de ancho. Se puede observar parte de lo que fue el muro hecho en base a tapiales (figura 07).

Muro 2b: Tiene 16,20 m de largo, $0.49 \mathrm{~m}$ de ancho y $2.60 \mathrm{~m}$ de alto (figura 08 ).

Muro 4a: Tiene $17 \mathrm{~m}$ de largo, $0.47 \mathrm{~m}$ de ancho y $2.60 \mathrm{~m}$ de alto (figura 09).

Muro 6: Tiene $7.20 \mathrm{~m}$ de largo, $0.47 \mathrm{~m}$ de ancho y $2.60 \mathrm{~m}$ de alto.

Recinto 2: Corresponde a dos espacios de planta trapezoidal que se encuentran delimitados por muros lo que le da la forma trapezoidal al recinto. Se encuentra asociado a un pasaje estrecho, el cual permite que exista una comunicación del recinto 2 con el recinto 3 (patio). Estos espacios evidencian un acceso restringido que sería sólo para el personaje de élite que la habría habitado. Tiene 13,60 m de largo y $10 \mathrm{~m}$ de ancho aproximadamente Al lado derecho del recinto se encuentra un vano de acceso de $1.20 \mathrm{~m}$ de alto y $0.65 \mathrm{~m}$ de largo y $0,60 \mathrm{~m}$ de ancho, el cual permite la comunicación entre el recinto 2 y el recinto 4 (figura 10).

Los muros que delimitan este recinto son: el muro 2a, el muro 6, el muro 9 y el muro 10.

Muro 2a: Tiene $15 \mathrm{~m}$ de largo, $0.50 \mathrm{~m}$ de ancho y $2.50 \mathrm{~m}$ de alto.

Muro 6: Tiene $7.30 \mathrm{~m}$ de largo, $0.49 \mathrm{~m}$ de ancho y $2.20 \mathrm{~m}$ de alto.

Muro 9; Tiene $13.10 \mathrm{~m}$ de largo, $0.60 \mathrm{~m}$ de ancho y $1.90 \mathrm{~m}$ de alto (figura 11).

Muro 10: Tiene $8.90 \mathrm{~m}$ de largo, $0.40 \mathrm{~m}$ de ancho y $1.90 \mathrm{~m}$ de alto (figura 12).

Recinto 3: Corresponde a un espacio amplio sin estructuras evidentes en su interior lo cual sugiere que sería un patio de forma trapezoidal, cuyos muros delimitantes son muros de tapiales. Su largo máximo es de $22 \mathrm{~m}$ aproximadamente y su ancho máximo es de 16,70 m aproximadamente (figura 13). 


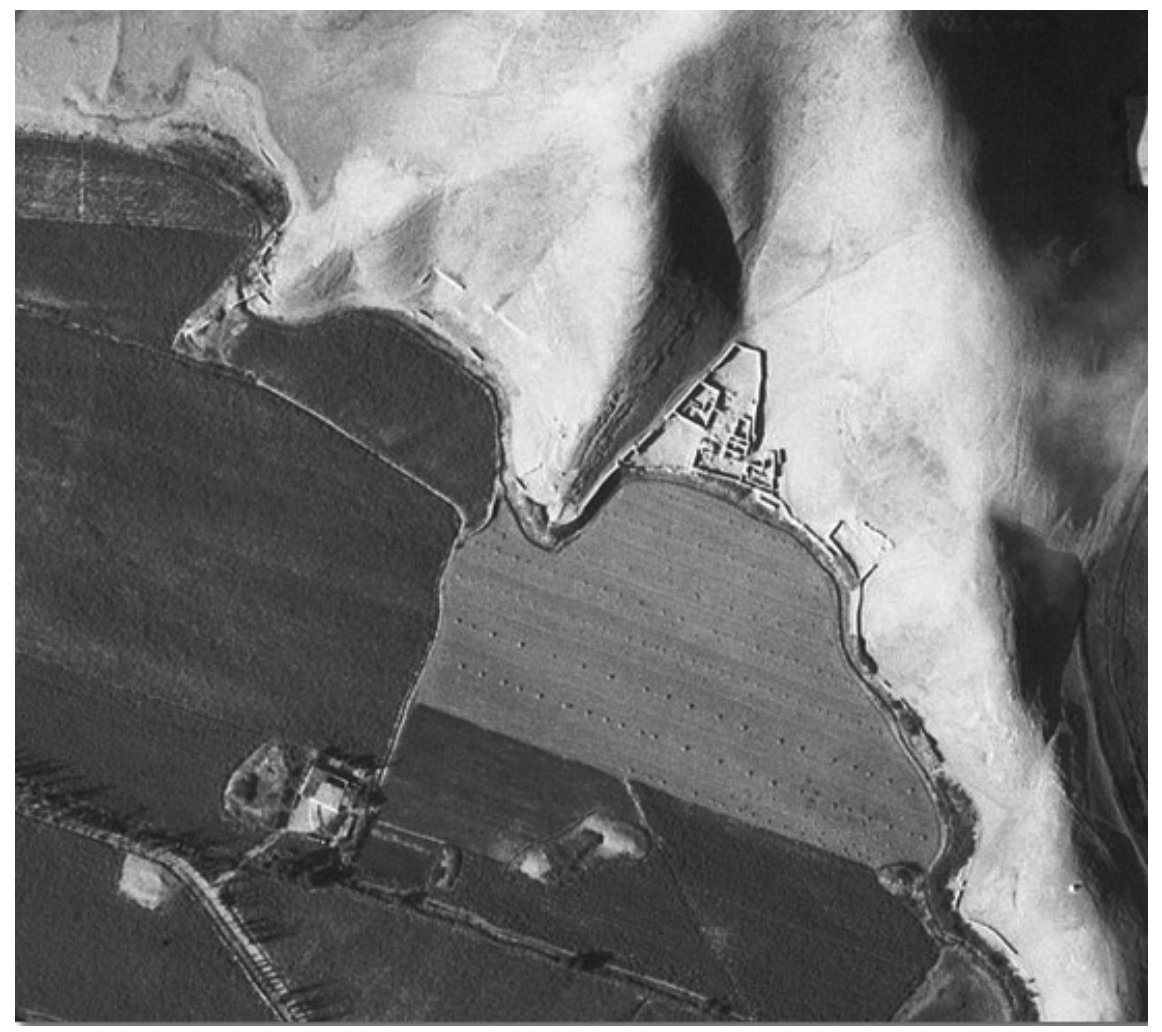

Figura 03. Foto aérea del sitio arqueológico palacio de Oquendo de 1945 (SAN, 1945).

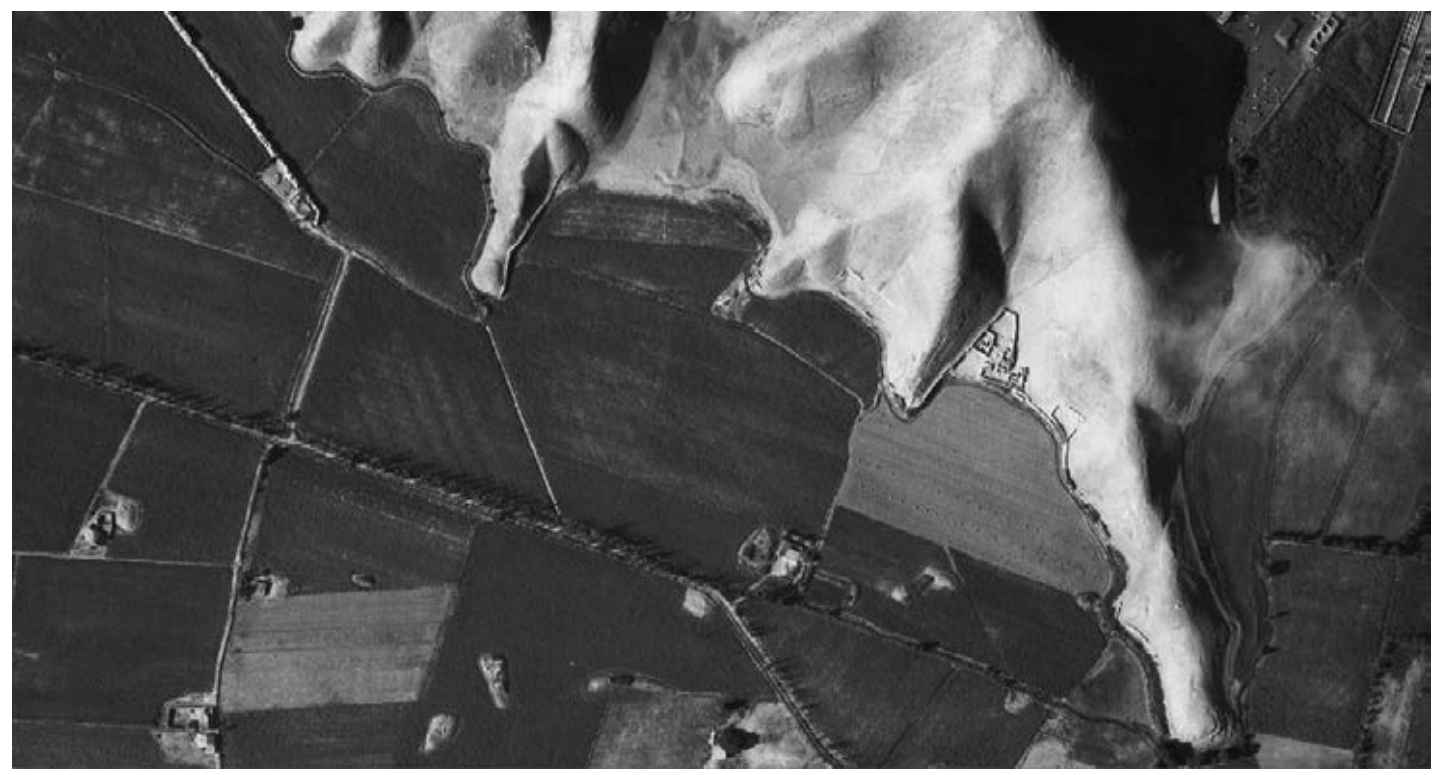

Figura 04. Foto aérea del sitio arqueológico palacio de Oquendo de 1945 (SAN, 1945). 


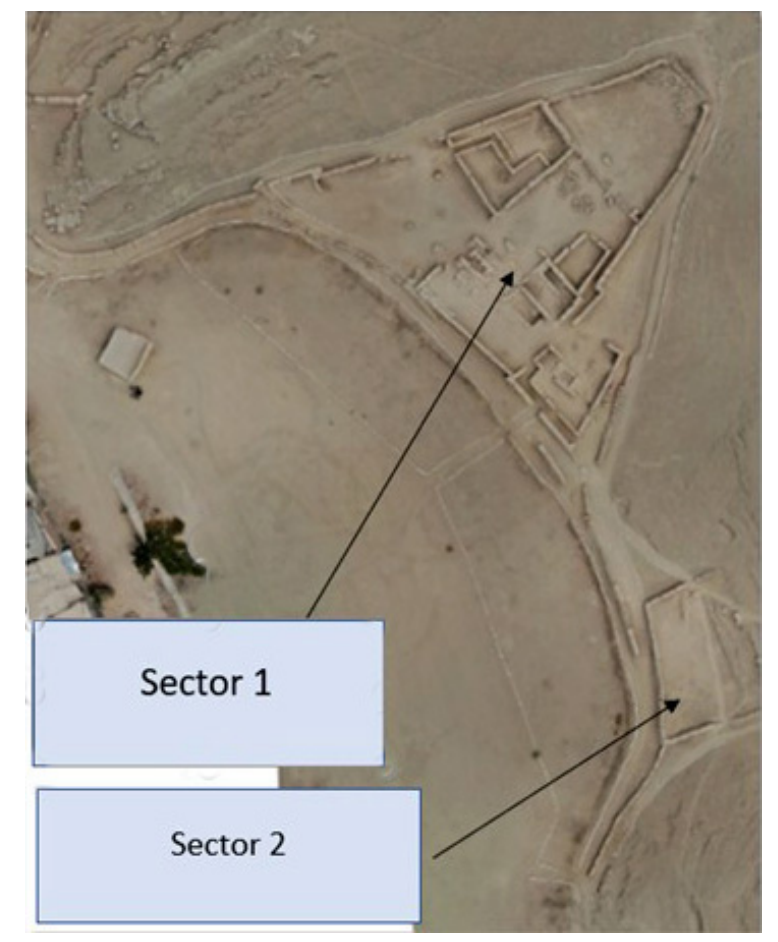

Figura 05. Sector 1 y Sector 2 de Palacio de Oquendo

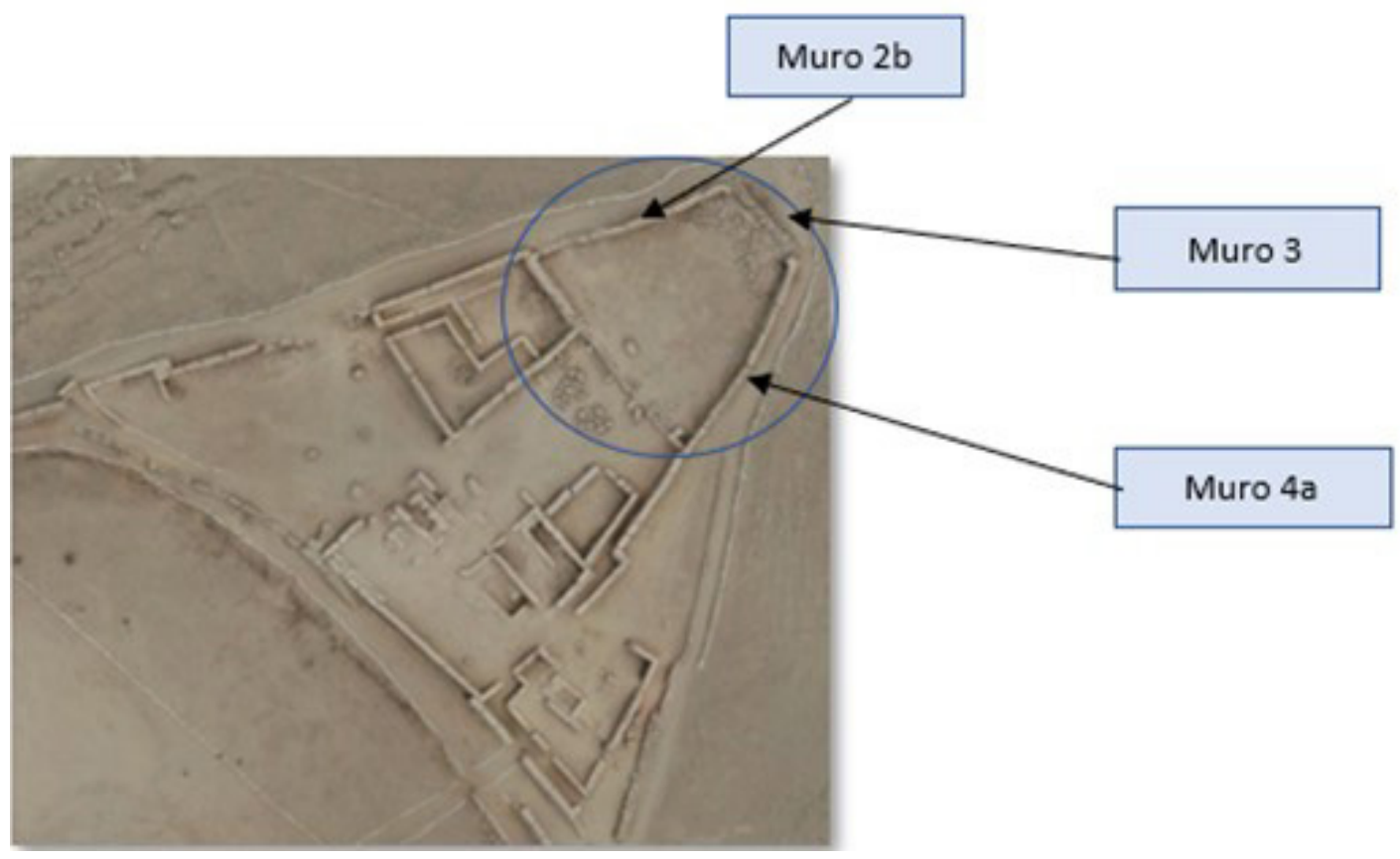

Figura. 06. Recinto 1. 


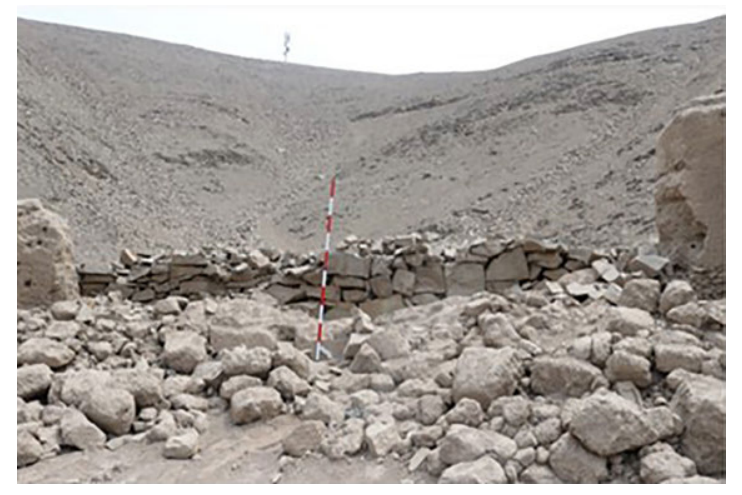

Figura 07. Muro 3

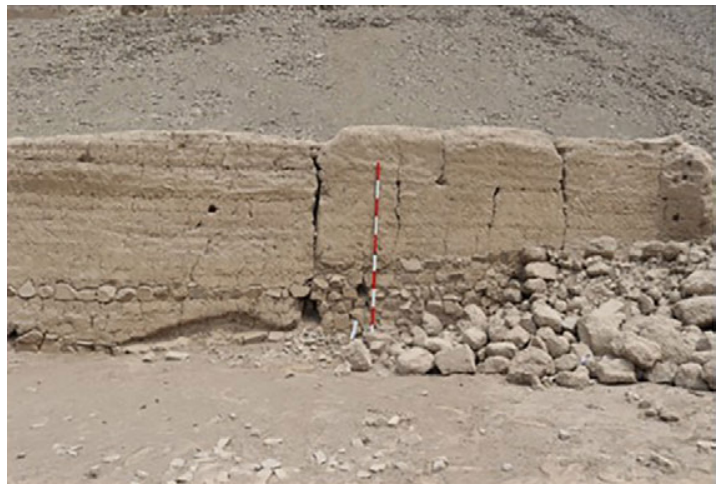

Figura 08. Muro $2 b$

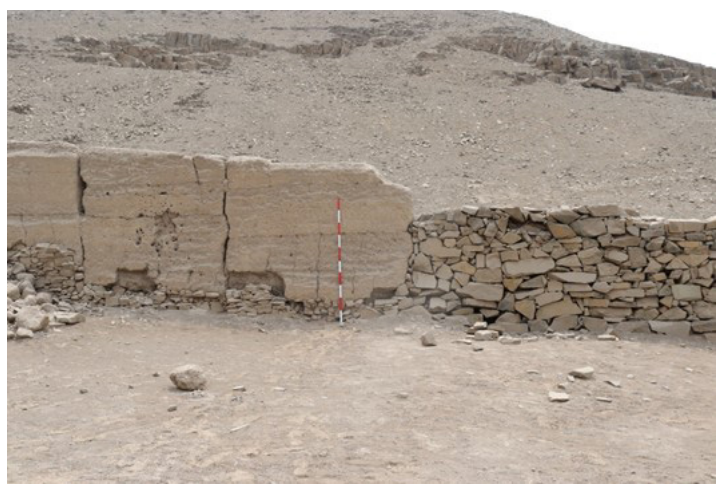

Figura 09. Muro 4a.

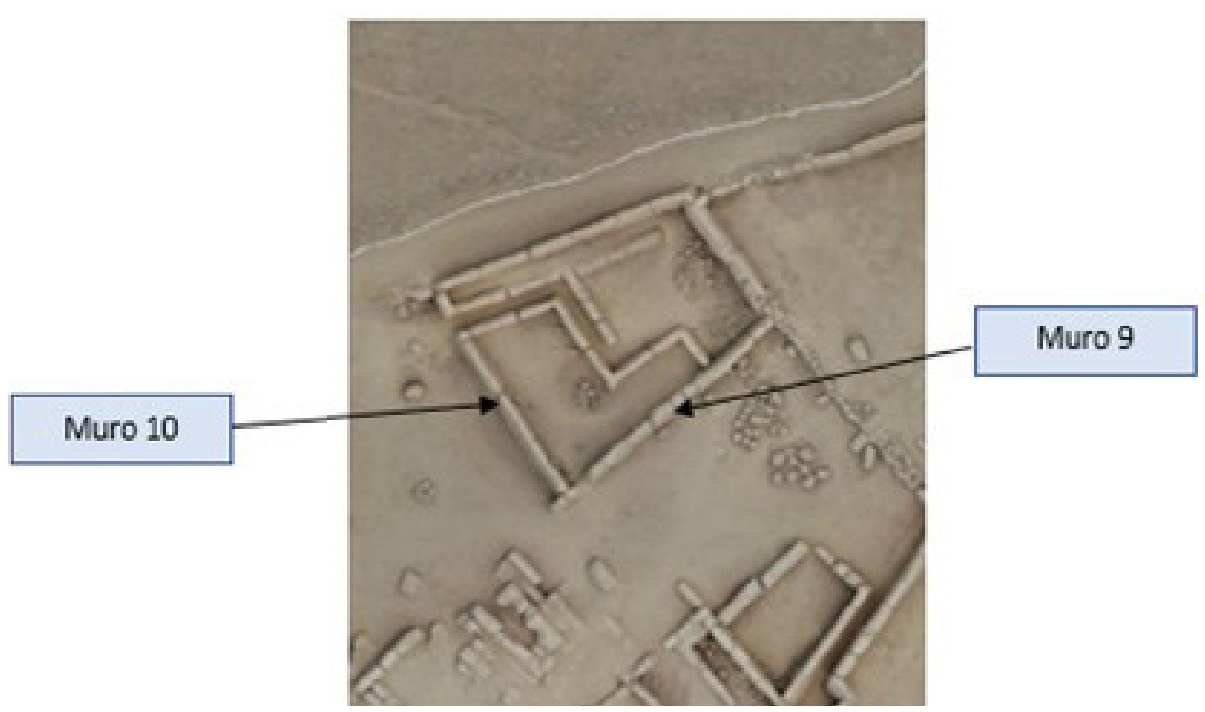

Figura 10. Recinto 2 


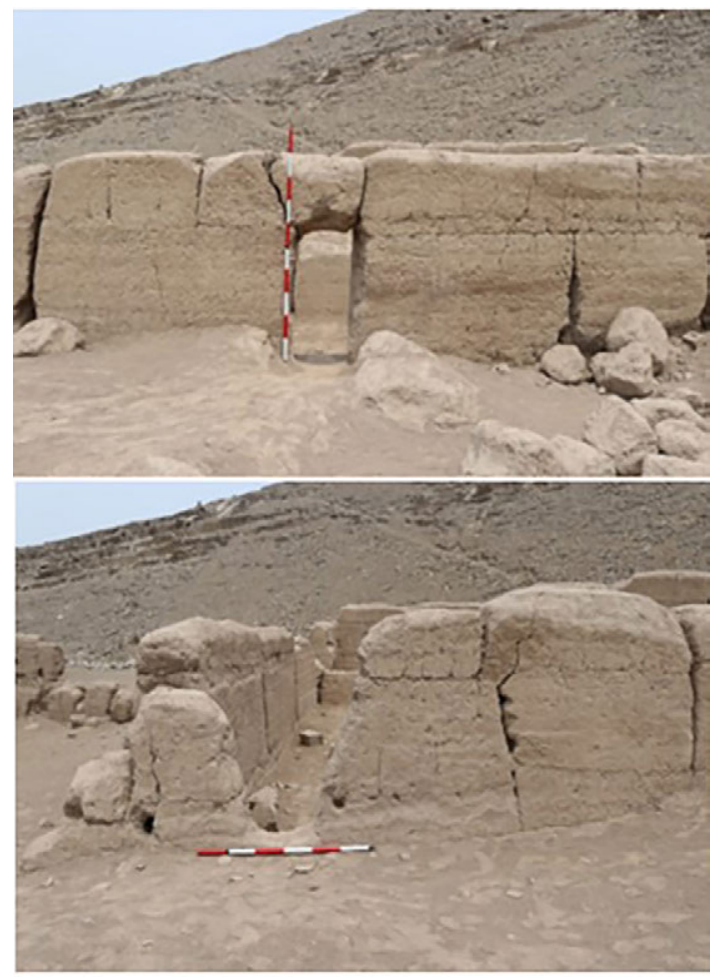

Figura 11. Muro 09

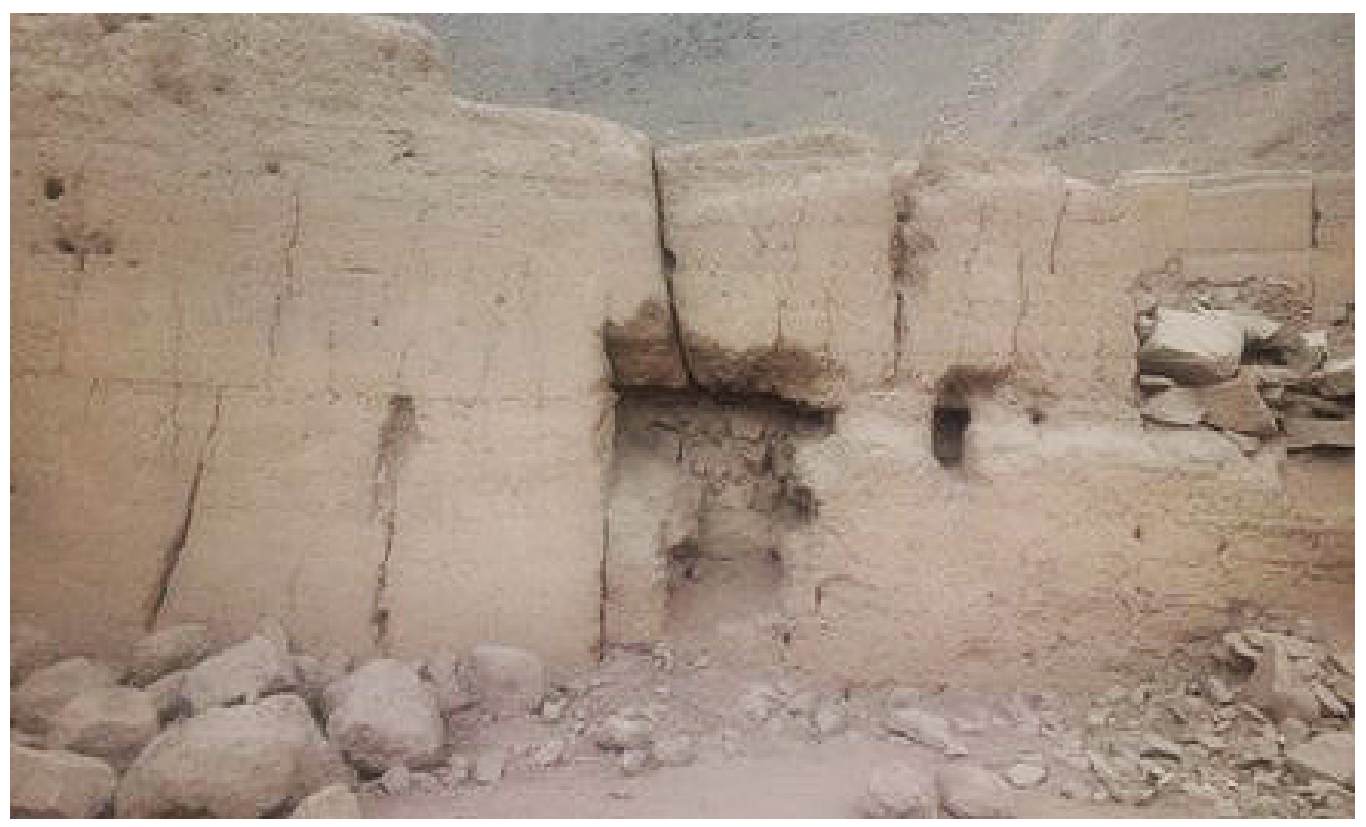

Figura 12. Muro 10 


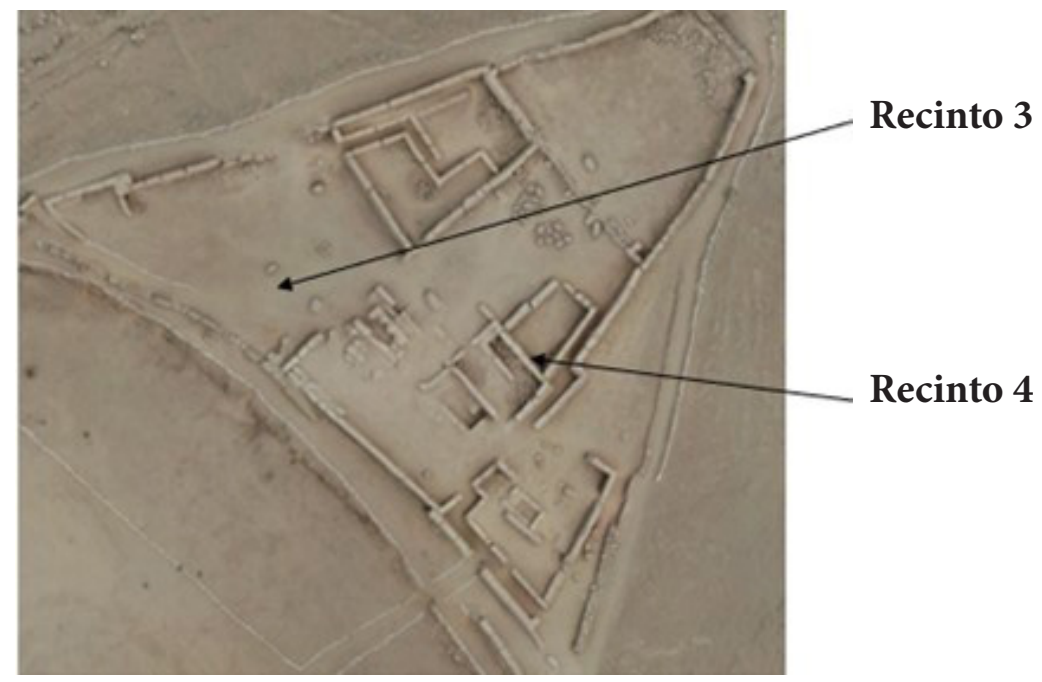

Figura 13. Recinto 3 y Recinto 4

Recinto 4: Corresponde a un espacio trapezoidal de $26 \mathrm{~m}$ de largo y 16,20 $\mathrm{m}$ de ancho aproximadamente (figura 13). Dentro del espacio se diferencia un amplio patio, estructuras cuadrangulares (figura 14) y un pasadizo angosto ubicado en la parte este del recinto, que permite la comunicación del recinto 4 con el recinto 5 ubicado al sureste del recinto 4 . Este recinto también evidencia ser un espacio reservado debido a que solo tienen comunicación con los demás recintos a través de un solo acceso bien un vano de acceso o un pasaje angosto como mencionamos. Los muros que delimitan el subsector tienen $6.40 \mathrm{~m}$ de largo, $0.43 \mathrm{~m}$ de ancho y $2.10 \mathrm{~m}$ de alto.

Los muros que forman parte del pasaje angosto son; el muro $4 \mathrm{~b}$, el muro 5, el muro 15 y el muro 19 (siendo estas dos últimas partes de las estructuras cuadrangulares mencionadas).

Muro 4b: Tiene $20.10 \mathrm{~m}$ de largo, $0.56 \mathrm{~m}$ de ancho y $2.20 \mathrm{~m}$ de largo (figura 15).

Muro 5: Tiene $5.50 \mathrm{~m}$ de largo, $0.54 \mathrm{~m}$ de ancho y $1.95 \mathrm{~m}$ de alto.

Muro 15: Tiene $6.40 \mathrm{~m}$ de largo, $0.43 \mathrm{~m}$ de ancho y $2.10 \mathrm{~m}$ de alto.

Recinto 5: Corresponde a un espacio delimitado de forma trapezoidal, cuyos muros son construidos a base de tapial, tiene $11 \mathrm{~m}$ de largo y $10 \mathrm{~m}$ de ancho aproximadamente (figura 16). Este recinto se encuentra conformado por estructuras cuadrangulares (figura 17) y se encuentra asociado a la entrada principal del sector 1. El pasaje que se encuentra al lado izquierdo (oeste) del recinto permite que el recinto 5 se pueda comunicar con el recinto 4 . El muro más representativo en este recinto es el 37 (figura 18), ya que a diferencia de otros muros presentes en el sector 1, presenta base de adobes y tapiales superpuestos, lo que indica otro tipo de construcción y segunda fase constructiva. Tiene $2 \mathrm{~m}$ de alto, $1.95 \mathrm{~m}$ de largo. 


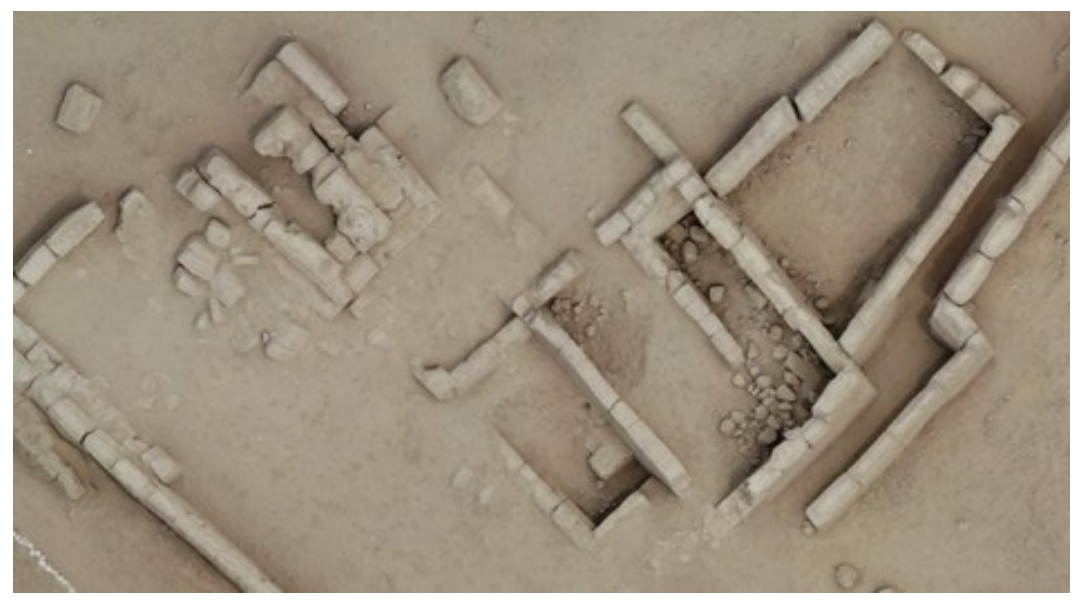

Figura 14. Estructuras cuadrangulares

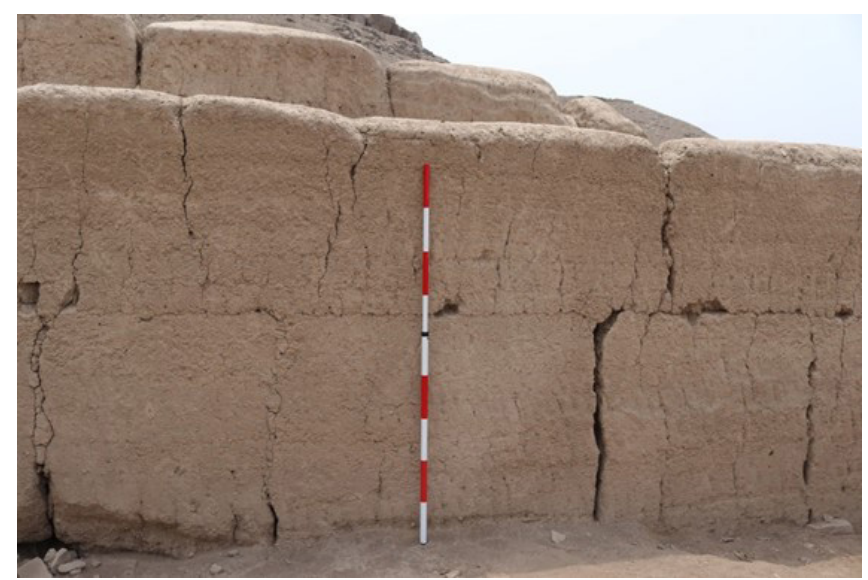

Figura 15. Muro $4 b$

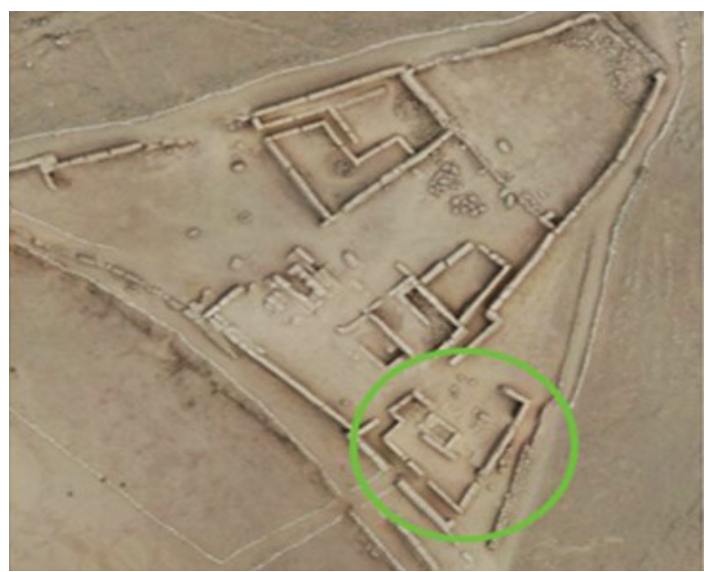

Figura 16. Recinto 5 


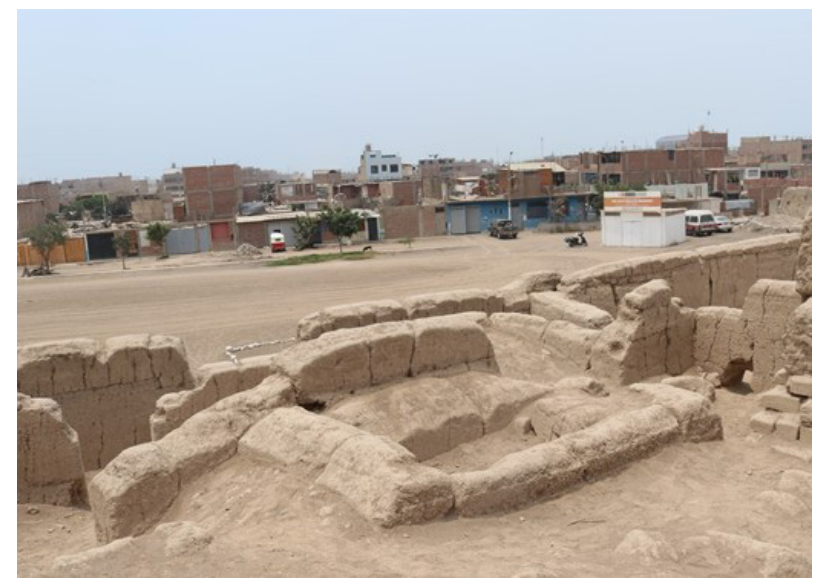

Figura 17. Recinto cuadrangular

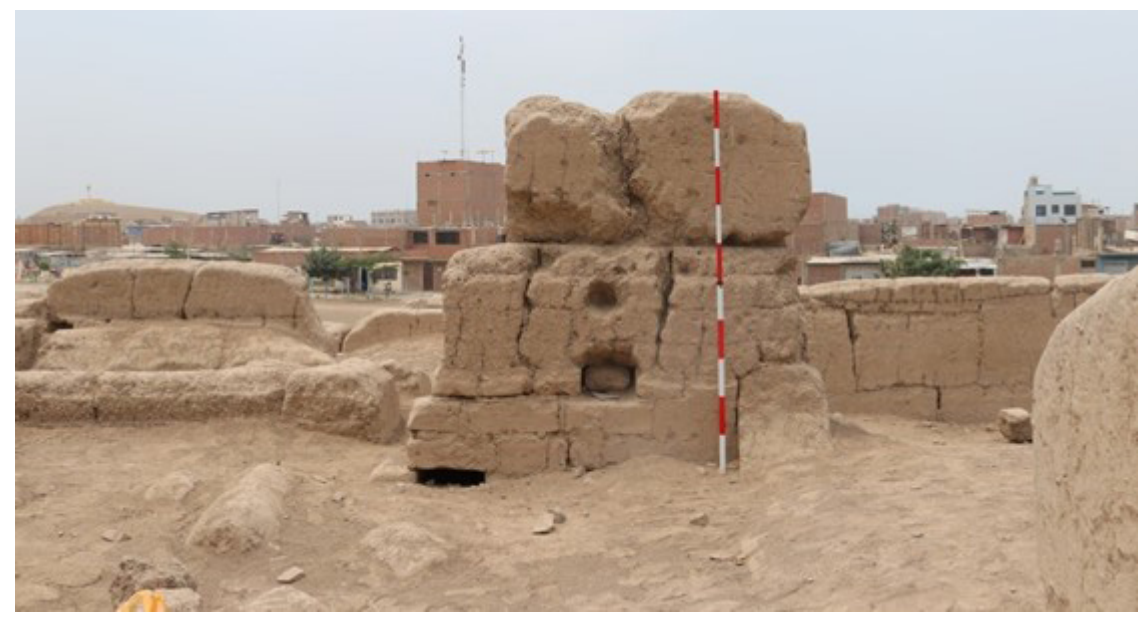

Figura 18. Muro 37

\section{Sector 2:}

El sector 2 se encuentra ubicado a $32.23 \mathrm{~m}$ aproximadamente del sector 1 . Su construcción se encuentra sobre un terreno inclinado (figura 19). Se encuentra delimitado por 4 muros (muro 1, 2, 3 y 4). Y tiene una forma rectangular.

Los muros tienen material constructivo a base de barro y hechas a través de la técnica del tapial.

Muro 1: Se encuentra ubicado continuamente al vano de acceso. Tiene 5,65 $\mathrm{m}$ de largo, $0.63 \mathrm{~m}$ de ancho y $2.10 \mathrm{~m}$ de largo (figura 20).

Muro 2: Se encuentra ubicado al lado sur este del sector. Tiene $18.20 \mathrm{~m}$ de largo, $0,45 \mathrm{~m}$ de ancho y $0.80-1.20 \mathrm{~m}$ de alto aproximadamente (figura 21 ). 


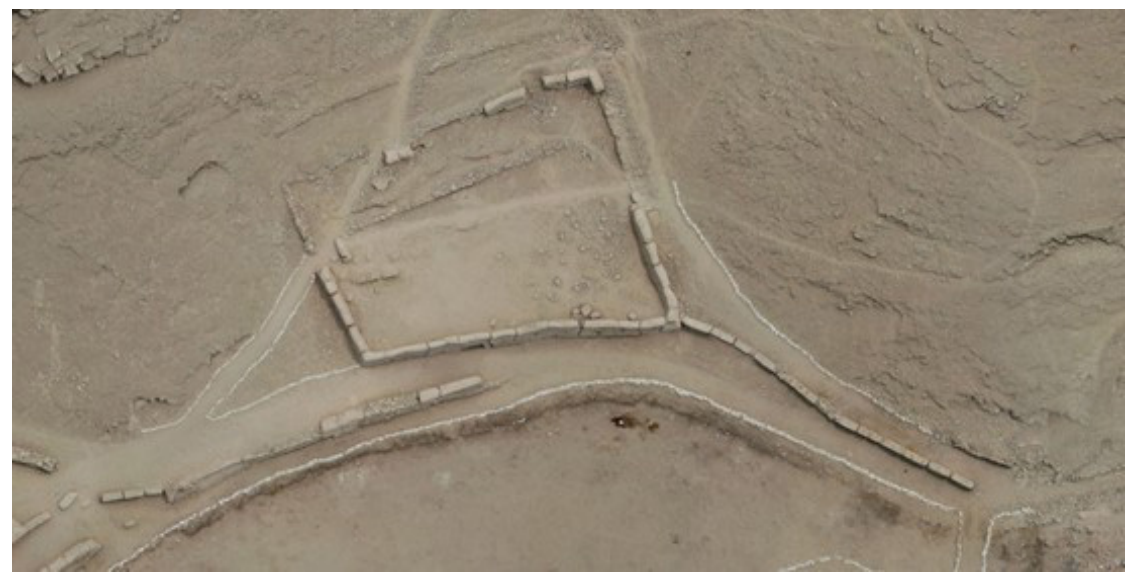

Figura 19. Sector 2

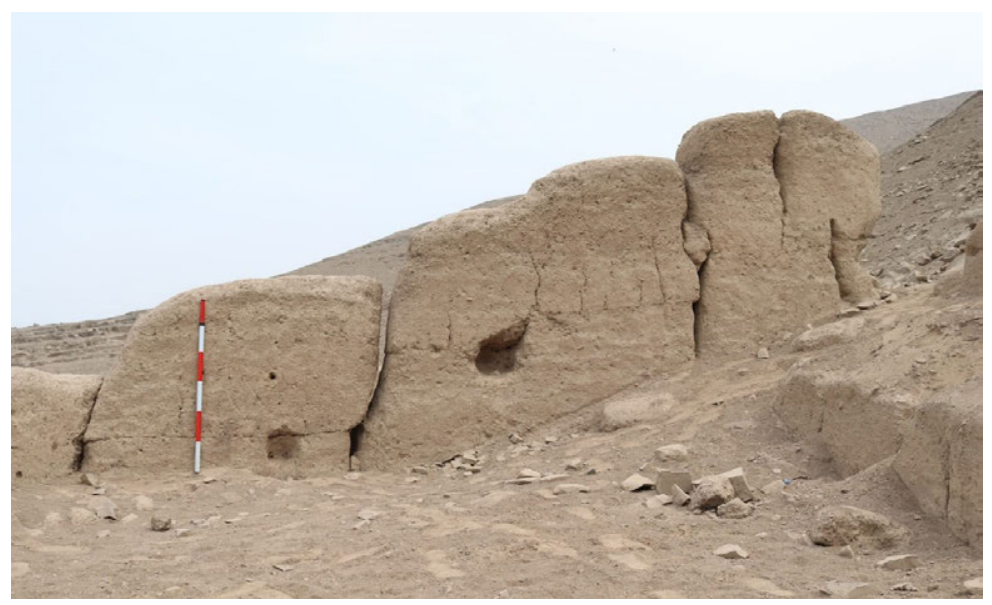

Figura 20. Muro 1

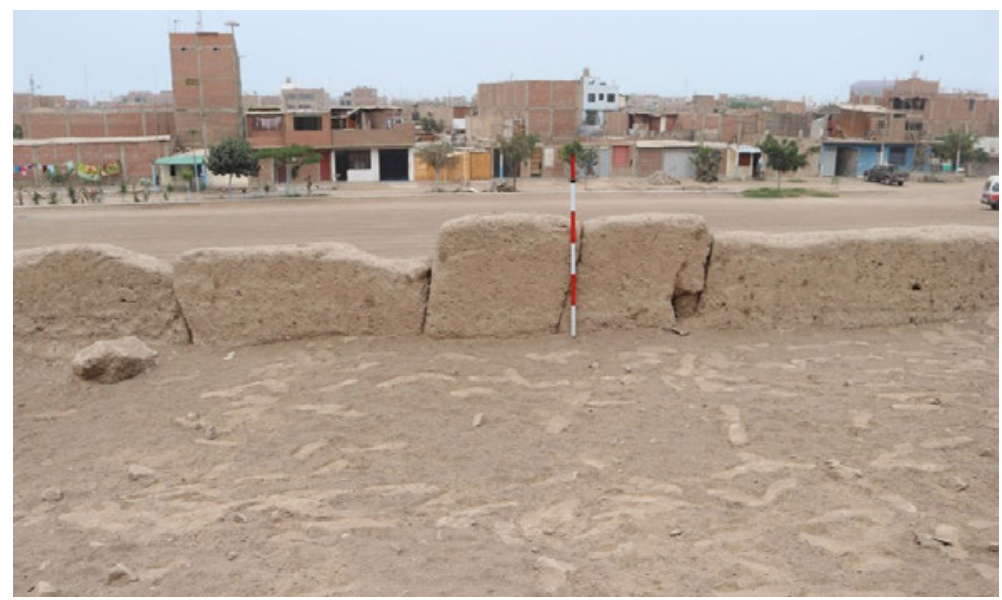

Figura 21. Muro 2 
Muro 3: Se encuentra ubicado al este del sector. Tiene 2,10 $\mathrm{m}$ de largo, 0,55 m aproximadamente de ancho y $2.15 \mathrm{~m}$ de alto aproximadamente (figura 22).

Muro 4: Se encuentra ubicado al norte del sector. Se observan los lineamientos del muro. Tienen $13 \mathrm{~m}$ de largo, $0.60 \mathrm{~m}$ de ancho y $2.10 \mathrm{~m}$ de alto (figura 23).

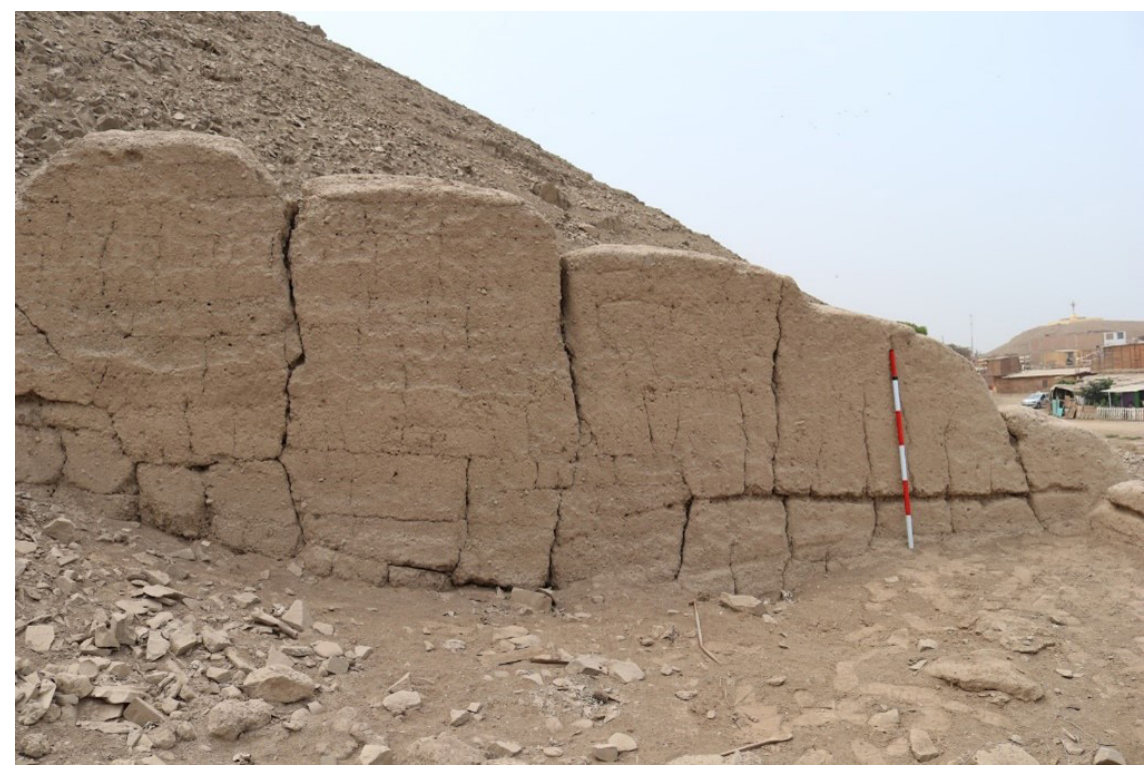

Figura 22. Muro 3

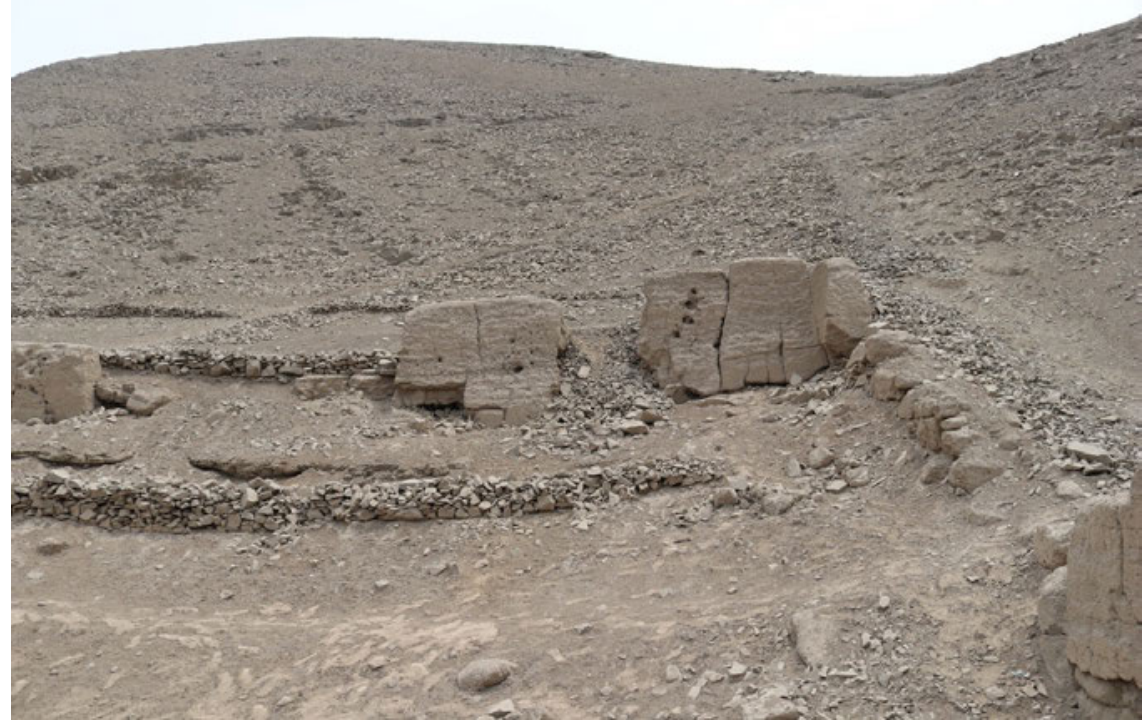

Figura 23. Muro 4 


\section{FUNCIÓN RESIDENCIAL DEL PALACIO DE OQUENDO}

\section{La asociación cronológica del sitio Palacio de Oquendo}

Las evidencias arquitectónicas que hemos registrado en el sitio arqueológico $\mathrm{Pa}$ lacio de Oquendo nos indica que este fue edificado en el Periodo Intermedio Tardío, durante el dominio de la formación sociopolítica de los Colli, continuando en uso hasta el Horizonte Tardío, es decir durante la ocupación Tawantinsuyu. Fue construido con materiales arquitectónicos en base a tapiales propios de los sitios de la Costa, con espacios diferenciados y restringidos con una distribución funcional.

\section{La funcionalidad del sitio Palacio de Oquendo}

El sitio arqueológico Palacio de Oquendo de acuerdo con el análisis superficial de los restos arquitectónicos, tanto en el sector 1 como en el sector 2 y la distribución espacial interna del sitio permiten inferir la cronología y la funcionalidad que se habría dado durante el Periodo Intermedio Tardío y que habría funcionado como una residencia de élite durante el Horizonte Tardío bajo el dominio incaico.

Autores como Villacorta (2004) denotan que una residencia de un gobernante dispone de un lugar más amplio a diferencia de las residencias convencionales que cumplen solo una función doméstica. En una residencia de élite convergen distintas actividades de carácter administrativo, social y político; cuya función principal es de controlar, almacenar, administrar los recursos, y las redes de intercambio (a través de la red vial a la que se encuentra asociado Palacio de Oquendo).

Villacorta (Ibíd.) establece características para definir a una residencia de élite, los cuales se pueden evidenciar en el sitio, como el tamaño del sitio, la ubicación estratégica, la asociación al camino inca, el uso de elementos y técnicas constructivas elaboradas, como la dimensión de los muros que encierran los recintos, donde se puede observar espacios reservados como pasajes angostos, espacios que habría habitado un personaje de suma importancia, así como también se puede evidenciar los espacios públicos, como los patios.

Eeckhout (2003) si bien es cierto adscribe las pirámides con rampa (PCR) como palacios, estos tienen características arquitectónicas que también denota que habrían sido ocupados por señores costeños importantes, lo cual sugiere que los ocupantes asumieron cargos seculares importantes en estas edificaciones cuya función es la de un palacio ocupado por un personaje de alto estatus.

Los palacios o residencias de élite son lugares de toma de decisiones es la clara muestra de la evidencia del poder. Es un lugar que presenta una arquitectura importante, donde se desarrollan diversas actividades, principalmente la de residir y pernoctar, como también otras series de funciones lo que lo hace un lugar multifuncional, evidenciando una jerarquización social, con un personaje de alto estatus a la cabeza y los súbditos cumpliendo sus roles designados por la élite. 
Si bien es cierto se encuentra en otro valle de Lima, es prudente mencionar al Palacio de Puruchuco, debido a que también presenta una continuidad en su ocupación y se pueden observar características similares con Palacio de Oquendo, en la composición arquitectónica propia de los palacios de la costa o residencias de élite. Puruchuco está rodeado de muros altos, al igual que Palacio de Oquendo, además de presentar patios, pasajes largos y angostos, denotando ambientes privados, espacios que se circulan a través de un vano de acceso.

\section{¿Quiénes construyeron el sitio Palacio de Oquendo?}

En base a los estudios que se han realizado en sitios arqueológicos ubicado en el valle bajo del río Chillón, tanto en Huaca Naranjal, Huaca Aznapuquio, Huaca Pro, Cerro Respiro, Tambo Inga, entre otros; se puede decir a manera de hipótesis, que la primera ocupación que habría tenido el sitio Palacio de Oquendo fue durante el Intermedio Tardío, cuya construcción se le atribuye a la formación sociopolítica Los Colli quienes se establecieron en el valle del río Chillón, y cuya sede principal se encuentra en la Fortaleza de Collique.

Los Colli y su establecimiento en el Chillón es conocido gracias a los datos etnohistóricos por parte de María Rostworowski quien menciona que durante el Intermedio Tardío existió un señorío denominado Colli quienes se establecieron desde el mar hasta la parte alta del Valle del río Chillón, hasta Santa Rosa de Quives.

A dicho señorío se adscriben una serie de curacazgos menores como Collec, Chuquitanta, Seuillay, Comas, Sutca y Carabayllo en el valle bajo; Sapan, Guancayo y Quibi en la margen izquierda de la cuenca media; y Macas, Guarauni y Missai en la margen opuesta de la misma sección del valle. Se menciona que los Colli bajo el mando de Colli Cápac cuyo dominio abrazaba la zona de Oquendo, Cerro Respiro, Aznapuquio, Huaca Pro, Fortaleza de Collique, entre otros poblados por distintos señoríos, los Colli era una entidad sociopolítica guerrera, belicosa, que constantemente tenían guerras con sus vecinos, los Canta.

Durante el Horizonte Tardío, el sitio Palacio de Oquendo habría tenido una continuación en su ocupación por los Incas, estos según la etnohistoria acaban con la vida de todos los hombres Colli debido a que no decidieron anexarse al dominio Inca, sino más bien sublevarse. Los incas bajo el mando de Túpac Yupanqui dominan la zona y pasan a apoderarse de la zona alta del Chillón donde se encontraban los cocales de Santa Rosa de Quivis.

Estos una vez establecidos crearon redes de caminos que interconectaba varios asentamientos debido a su importancia que tenían durante la época, el cual también el sitio Palacio de Oquendo se encuentra asociado a un tramo del camino Inca, el cual denota la importancia que tuvo para los incas su establecimiento. 


\section{CONCLUSIONES}

El sitio arqueológico Palacio de Oquendo se encuentra en el pie del cerro de Oquendo, conformado por elementos arquitectónicos dispuestos en una plana de trazo ortogonal y trapezoidal. Con estructuras construidas en la técnica de tapial. Los muros de tapiales que están definiendo y dividiendo los espacios interiores de los dos sectores con los que cuenta el sitio arqueológico Palacio de Oquendo distribuidos en un área de 3 hectáreas aproximadamente.

La ubicación y emplazamiento del sitio Palacio de Oquendo evidencia la importancia de su construcción en el valle bajo del río Chillón. Su construcción denota que fue planificada y tuvo un rol importante durante el Tawantinsuyu debido a que se encuentra asociado al camino Inca. El camino inca, tiene un recorrido tanto longitudinal como transversal el cual unía a sitios de especial interés, como es el caso de Palacio de Oquendo en la margen izquierda del Valle bajo del río Chillón. Los sitios que se encuentran unidas a la red vial inca habrían sido planificados y cumplían el rol de contribuir a modelar el espacio y satisfacer una determinada función administrativa. Los caminos serían del tipo camino epimural según Silva, el cual se caracterizan por presentar muros altos y contar con escaleras de accesos en algunos tramos. El presentar parte la red vial inca denota la gran importancia que tuvo el sitio.

Los elementos arquitectónicos sugieren que habrían tenido dos fases constructivas, esto se puede evidenciar en muros que se encuentran adosados a otros más antiguos, y a la distinta técnica constructiva. Como en el caso del recinto 5, en el cual hay un muro que fue construida a base de adobes a diferencia de los demás muros. En el sector 1, el área residencial de élite se observa una mayor disposición de recintos y espacios públicos relacionados con la actividad económica. Se evidencia a partir de las estructuras presentes, los pasajes que se encuentran comunicando unos espacios de otros, a través de vanos de acceso y pasadizos angostos, el cual evidencia un carácter privado y jerárquico, que habría sido habitado por un personaje de alto estatus.

En el sector 2, comprende una construcción adicional al sector 1, elaborada en base a la técnica del tapial, constituido por muros del mismo tipo de material constructivo, y un vano de acceso que permite la entrada hacia el interior. El cual estaría siendo utilizado para procesamiento de los productos y actividades económicas. Las evidencias arquitectónicas que hemos registrado en el sitio arqueológico Palacio de Oquendo nos indica que este fue edificado en el Periodo Intermedio Tardío, durante el dominio de la formación sociopolítica de los Colli, continuando en uso hasta el Horizonte Tardío, es decir durante la ocupación Tawantinsuyu.

Con respecto a la conservación del sitio Palacio de Oquendo, se encuentra en regular estado, ya que por causa del avance urbano y la intermisión de personas del asentamiento actual en el lugar se han ido deteriorando a través del tiempo y también por causa de agentes naturales propios de la ecología en la que se encuentra ubicado. 
Agradecimientos: El presente trabajo de investigación forma parte del curso Practicas Pre Profesionales, obteniendo la financiación en el tercer concurso del Programa de Promoción de trabajo de investigación para optar el grado de Bachiller, por parte del Vicerrectorado de Investigación y Posgrado de la Universidad Nacional Mayor de San Marcos, titulado "El Palacio de Oquendo, una residencia de élite en el valle bajo del río Chillón" (E20150160c), aprobado mediante Resolución Rectoral 016948-2020-R/UNMSM de fecha 11 de noviembre de 2020, proyecto registrado por la Escuela Profesional de Arqueología (oficio del 21 de setiembre de 2020), bajo la asesoría del Dr. Pieter van Dalen Luna. En estas líneas quiero agradecer el apoyo incondicional de mis padres tanto económica como emocionalmente, que fue fundamental para lograr concluir el presente trabajo.

Agradezco a cada uno de mis docentes en estos cinco años en la universidad, por compartir sus conocimientos, sobre todo en el curso de Prácticas Pre Profesionales a cargo de la docente Luisa Díaz Arriola. A mis compañeros de aula por participar en las prospecciones que realicé en el sitio, a Yomira Huaman, Tania Ramírez, Rosa Milla, Flor Conza, Jhefer Gavino y Josselin Chávez. Asimismo, agradecer a mi asesor de tesis al Dr. Pieter Dennis van Dalen Luna, quien me brindó la confianza y la oportunidad para poder adentrarme en proyectos de investigación arqueológica y así ir desarrollándome profesionalmente. También por comprometerse en el desarrollo y conclusión de la tesis que presentaré.

\section{REFERENCIAS BIBLIOGRÁFICAS}

Agurto Calvo, S. (1984). Lima Prehispánica. Lima: Municipalidad de Lima.

Agurto Calvo, S. (1987). Construcción arquitectura y planeamiento Incas. Lima: Cámara Peruana de la Construcción.

Ayala, R. (2008). El sitio arqueológico Cerro Respiro: Un caso de residencia de élite inca en el valle bajo de Chillón. Tesis de Licenciatura en Arqueología. Lima: Facultad de Humanidades, Universidad Nacional Federico Villarreal.

Astuhuamán, C. (2013). La función de la arquitectura inca de élite en el extremo norte del Perú. Cuadernos del Qhapaq Ñam, (1), 8-31.

Dillehay, T. (1987). Estrategias Políticas y económicas de las etnias locales del valle del Chillón durante el periodo prehispánico. Revista Andina (2), 407-456. Cusco: Centro Bartolomé de las Casas.

Eeckhout, P. (2003). Diseño arquitectónico, patrones de ocupación y formas de poder en Pachacamac, Costa central del Perú. Revista Española de Antropología Americana, (33), 17-37. https://revistas.ucm.es/index.php/REAA/article/ view/REAA0303110017A 
Espinoza Tapia, L. (2008). Huaca Aznapuquio: nuevos datos sobre ocupación humana, recursos hídricos y territorio étnico en la cuenca baja del Chillón. Arqueología y Sociedad, (19), 129-157.

Farfán, C., Bautista, C. y Raymondi A. (2014). Arqueología del valle del Chillón: patrones de asentamiento tardío. Cátedra Villarreal, 2(1), 73-86. Lima.

Mackey, C. (1987). Chimu Administrative in the Provinces. En J. Hass, S. Pozorski \& T. Pozorski, (Eds.). The Origins and Development of the Andean State (pp. 121129). Cambrigde University Pres.

Maquera, Erik. (2008). Huaca Naranjal: Un centro de producción de ceramica estilo Ychsma en el valle del Chillón. Arqueología y Sociedad, (19), 67-82. Museo de Arqueología y Antropología UNMSM.

Pillsbury, J. (2004). The Concept of the Palace in the Andes. En: Susan Evans y Joanne Pillsbury (Eds.). Palaces of the Ancient New World (pp. 181-189). Washington D.C. Dumbarton Oaks Research Library and Collection.

Pulgar Vidal, J. (2014). Las ocho regiones naturales. INTE-PUCP: Compañía de Minas Buenaventura. Lima

Raymondi, A. (2014). Ocupaciones prehispánicas tardías en el valle bajo del Chillón: Una aproximación desde la Huaca Pro. Arqueología y Sociedad, (28), 9-42. Museo de Arqueología y Antropología UNMSM.

Rostworowski, M. (1972). Las etnias del Valle del Chillón. Revista del Museo Nacional, 38, 250-315. Lima.

Silva Sifuentes, J. (1996). Patrones de Asentamiento en el valle del Chillón. Tesis Doctoral de Philosophy (Anthropology), University of Michigan, USA.

Villacorta, Luis F. (2004). Los palacios en la costa central durante los periodos tardíos: de Pachacamac al Inca. Bulletin de l'Institut français d'études andines, 33 (3), 539-570.

Wason, P. (1996). The Archaeology of Ran. Cambridge: Cambridge University Press. 


\section{SOBRE LA AUTORA}

\section{Noelia Allcca Aiquipa}

Inició sus estudios superiores en la EAP de Arqueología en la Universidad Nacional Mayor de San Marcos en el año 2016 y egresó en febrero del año 2021.

En el año 2020 durante sus estudios en la UNMSM, participó y ganó en el concurso de financiamiento del VRIP, con su trabajo de investigación titulado "Palacio de Oquendo, una residencia de élite en el valle bajo del río Chillón" .

Su interés académico es investigar periodos tardíos: Intermedio Tardío y Horizonte Tardío. Actualmente investiga la zona baja del valle del río Chillón. 